Corinne Rosenblum

MCRP Student

City and Regional Planning Department

Cal Poly San Luis Obispo

\section{GIS “Wows” Planners: Real-time Analysis of Land Use Allocations Using GIS}

The author comments on her participation in a community visioning process as a graduate student and GIS specialist. She shows how integrating GIS technology into public workshops can increase support for database technologies, enhance the community's planning process, and increase stakeholder involvement.

Embarking on a new path; I arrived in San Luis Obispo August 10, 2003 to begin the Masters of City and Regional Planning program at California Polytechnic State University. What did I know about the planning profession? Not much, but I did know GIS (Geographic Information Systems). I spent the previous four years working for a GIS Consulting firm in Boston. We developed GIS data and trained local municipalities on how to query for parcels, create abutter's lists, view zoning maps, etc.

Shortly after I arrived in San Luis Obispo, in search of a part-time job and extracurricular experience, I met professor Walt Bremer at the Landscape Architecture GIS Lab. The GIS Lab wanted my help on a contract with the San Luis Obispo Council of Governments (SLOCOG) to assist with the technical aspects of several future visioning workshops. It was the perfect opportunity to earn money and build connections within the community.

\section{PROGRAM BACKGROUND}

SLOCOG (San Luis Obispo Council of Governments) received a grant from Caltrans (California State Department of Transportation) to conduct visioning workshops throughout the county using a GIS modeling tool called Place3s, which stands for PLAnning for Community Energy, Environmental \& Economic Sustainability. The model was originally developed through the joint coordination of the state energy departments in California, Oregon, and Washington as an extension to ESRI's ArcView 3.x software (http://www. energy.ca.gov/places/). It has since been migrated to a web version by EcoInteractive, Inc. (http://www.ecointeractive. $\mathrm{com} /$ ) in conjunction with the Sacramento Area Council of Governments (SACOG) as part of their "Blueprint" project (http://www.sacregionblueprint.org). The web-based software was designed to be used in a public workshop environment. It is simple enough for computer savvy participants to learn, however it's recommended to have trained computer operators be at each table. These operators input participants' land use proposals into Place3s during the workshop and provide "live" feedback on the impacts of those proposals. With Place3s at every table, the effects of proposed changes can be viewed, measured, and discussed during the creative process.

\section{TYPICAL IMPLEMENTATION OF PLACE3S}

The Place3s model requires several data inputs. Along with a GIS base map, one of the most important inputs for our community visioning exercises was the set of development types. Development types contain numerical assumptions such as density of residential units, employees per acre, floor area ratios, and more. As with any model, more precise information input at the beginning, leads to higher quality information produced from the model.

At the visioning workshops, participants were given a "menu" of development types consisting of existing and potential land uses. Their task was to identify ideal (or likely future) locations for such land uses, as well as development types by placing representative stickers on a paper map. Participants were able to address issues of growth by evaluating whether increasing housing density or revitalizing neighborhoods through pedestrian friendly retail and additional businesses would result in a better future than continuing with current development trends. A computer operator at the table input the development type placements and reported the number of employees and dwelling units added (or removed) throughout the exercise. This allowed participants to gage their progress and understand the effects of their land use allocations. SLOCOG collaborated with Fehr \& Peers (http://www.fehrandpeers.com/), a transportation consultant, to integrate a traffic-modeling component with Place $3 \mathrm{~s}$ at the two regional workshops. 


\section{WORKSHOP PRACTICE}

The original intention for using Place $3 \mathrm{~s}$ in visioning workshops throughout San Luis Obispo County was to assist with updating the General Plan Housing Elements. Unfortunately, by the time the grant paperwork was signed, the jurisdictions had completed the public participation phase of the Housing Element updates. This left SLOCOG with a grant for workshops and no jurisdictions eagerly seeking the kind of thing Place3s could do for them. Shortly after I joined the effort in August 2003, Arroyo Grande signed on as the first jurisdiction to test the model in San Luis Obispo County. The San Simeon Earthquake derailed plans to move forward with the project in Paso Robles and Atascadero as the need to address earthquake recovery consumed staff time and resources.

The workshop in Arroyo Grande was beneficial in that we set up and coordinated the full visioning exercise. Unfortunately, the participants were not residents. They were planners who now know how to integrate Place3s into the planning process. The objective of the Arroyo Grande workshop was to evaluate the East Grand Avenue area for its potential to accommodate low and moderate income housing, as part of a revitalized mixed use corridor, to meet the current Housing Element goals. This proved to be a difficult task because the development types were not dense enough to meet the target population. The largest lesson we learned from the Arroyo Grande workshop is this: Practice the exercise in advance to ensure it meets the goals before bringing it to the public.

\section{LOCAL WORKSHOP SUCCESS}

The first real success story of using Place3s in San Luis Obispo County was the series of workshops held in Grover Beach. The City of Grover Beach hired DC\&E (http://www. dceplanning.com/) to coordinate three workshops and provide a resulting report of suggested amendments to the General Plan Land Use Element. During the first workshop, participants determined issue areas within the community. They narrowed the scope of discussion primarily to the main commercial corridors of Grand Avenue and North 4th Street as well as the predominantly industrial areas along the railroad right-of-way and south of Farroll Road. At the second workshop, the participants used large maps and stickers coordinated with the Place3s model to designate ideal land uses along these corridors. The provided development type menu used in these workshops is shown as Figure 1.

At each of the ten tables, participants used stickers and markers to indicate on 24"x 36 " maps their preferred development types for the issue areas. A computer operator at each table input this information and reported back the change in number of jobs and dwelling units as the participants worked.

Figure 1. Development types for the workshop, Grover Beach Visioning Project
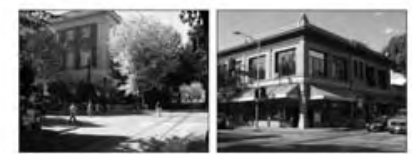
noxe use-riece stonica

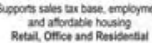
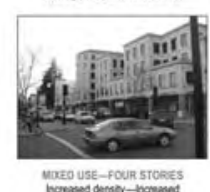

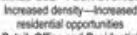

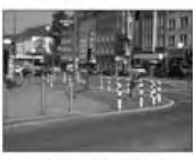

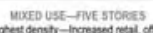

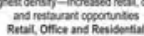

COVuercul-sTREer FRONT Supposts siles ax base ind
encolompent

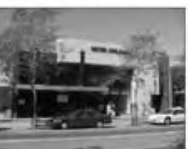

COMUERCIN RETAL

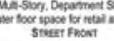
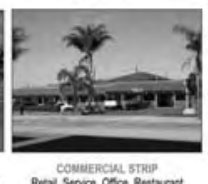

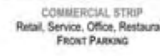
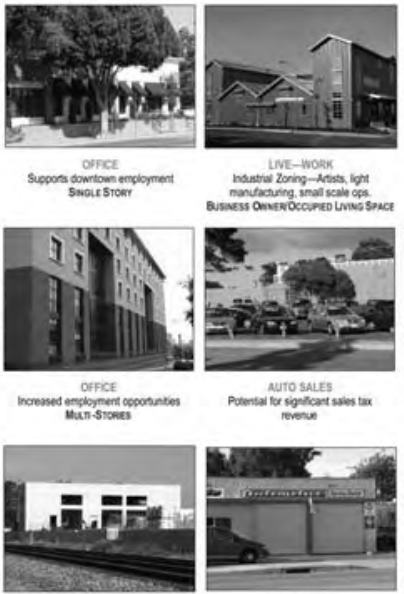

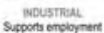

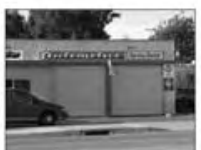

AUTO REVAalt

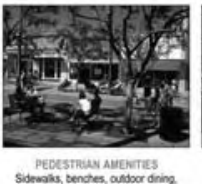

Sidewals, bencies, audsor dining
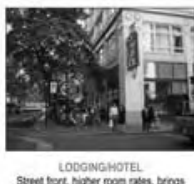

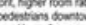

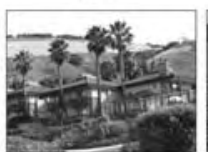

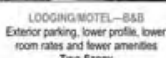

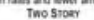

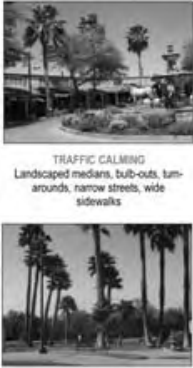

PARSS S RECREATIOY

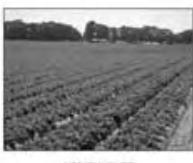

Ansiculture 
At the end of the second workshop, each table presented their maps and ideas to the rest of the group. Figure 2 shows one of the completed table maps. We displayed each groups' total number of jobs and dwelling unit change on a large screen at the front of the room. This allowed the participants to compare their results with those of other tables and understand the impacts of different land use applications. A sample comparison table is shown as Table 1.

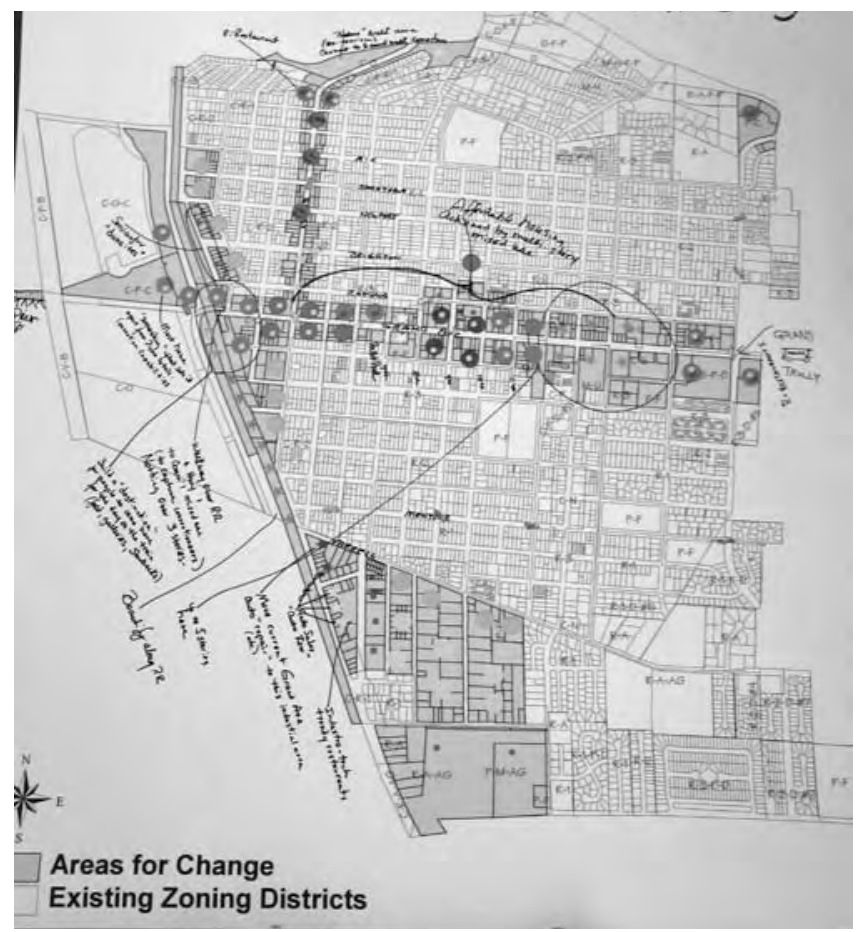

Figure 2. Participant comments from the Grover Beach workshop
After the second workshop, DC\&E synthesized the participants' feedback and developed three land use development scenarios depicting high, medium, and low intensity growth alternatives for the future of Grover Beach. These are shown as Figure 3. These alternatives were presented at the third and final workshop of the series to attain refined feedback from the participants. The feedback from all three workshops was incorporated into DC\&E's final report of suggestions for Grover Beach's Land Use Element.

\section{REGIONAL WORKSHOPS}

A partnership of regional agencies led by SLOCOG hosted two regional visioning workshops on January 22nd, and February 5th 2005 in Nipomo and Templeton respectively. Both workshops were very well attended by concerned residents of the community. Trained Cal Poly students facilitated the tables and input the proposed land uses into Place3s through laptops and a wireless internet connection.

At these Saturday morning workshops, participants were encouraged to think about growth impacts on a regional scale. Each workshop focused on half of the county in terms of land area, population, employment, and transportation. The development types depicted regional categories such as city, town, and village, rather than specific land uses. Participants discussed whether already urbanized areas should grow up or grow out into farmland and open space. The workshops resulted in an overwhelming consensus to develop near existing traffic corridors. Participants chose development types resulting in compact growth as an effort to preserve the small town character of San Luis Obispo County. A summary session is planned for March 11th, 2005 in San Luis Obispo to present and discuss the results of the two regional workshops. The objective of the summary session is

\begin{tabular}{|l|c|c|c|c|c|c|}
\hline & $\begin{array}{c}\text { Total } \\
\text { Employees }\end{array}$ & $\begin{array}{c}\text { Employees } \\
\text { per Acre }\end{array}$ & $\begin{array}{c}\text { Employees per } \\
\text { Dwelling Unit }\end{array}$ & $\begin{array}{c}\text { Total } \\
\text { Dwelling } \\
\text { Units }\end{array}$ & $\begin{array}{c}\text { Dwelling } \\
\text { Units per Acre }\end{array}$ & $\begin{array}{c}\text { Total } \\
\text { Polulation } \\
\text { Change }\end{array}$ \\
\hline BASE CASE & 4,657 & 21.2 & 8.84 & 527 & 10.22 & 0 \\
\hline SCENARIO 1 & 8,117 & 37.02 & 3.66 & 2,215 & 34.52 & 4,314 \\
\hline SCENARIO 5 & 7,762 & 33.22 & 5.15 & 1,508 & 34.22 & 2,508 \\
\hline SCENARIO 9 & 7,221 & 31.08 & 3.27 & 2,206 & 35.83 & 4,290 \\
\hline
\end{tabular}


to reach consensus as a community on how to regionally plan for the kind of growth indicated in the workshops.

\section{CONCLUSION}

The experiences so far, particularly the series of Grover Beach workshops, demonstrate the usefulness of a technical tool such as Place3s in a workshop environment. Participants enjoyed the exercise and were "wowed" by the immediate results of their land use allocations. They were able to develop a high level of consensus regarding key issues in a short period of time.

Workshops with visible GIS technology can increase support for this and other database technologies. They also have the potential to enhance the community's planning system and increase stakeholder involvement. It is important to note, Place $3 \mathrm{~s}$ is just a modeling tool. As in Grover Beach, it is most successfully utilized in conjunction with a planned program for public participation. Background information and base data are necessary for the model to operate successfully. Information on all San Luis Obispo County workshops can be found at http://landarch.calpoly.edu/place3s/.

\section{POST-SCRIPTUM: A NOTE TO INTERESTED COMMUNITIES}

Several GIS visioning tools, similar to Place3s, are available. Each one serves a different purpose and is useful for different goals local governments may have. I recommend that each locality look at available models and determine the best one for issues particular to their community. Information about technical tools for public workshops can be found at http:// www.smartgrowthtools.org/index.php.Informationregarding conferences where participants can use and evaluate different tools can be found at http://www.placematters.us/.
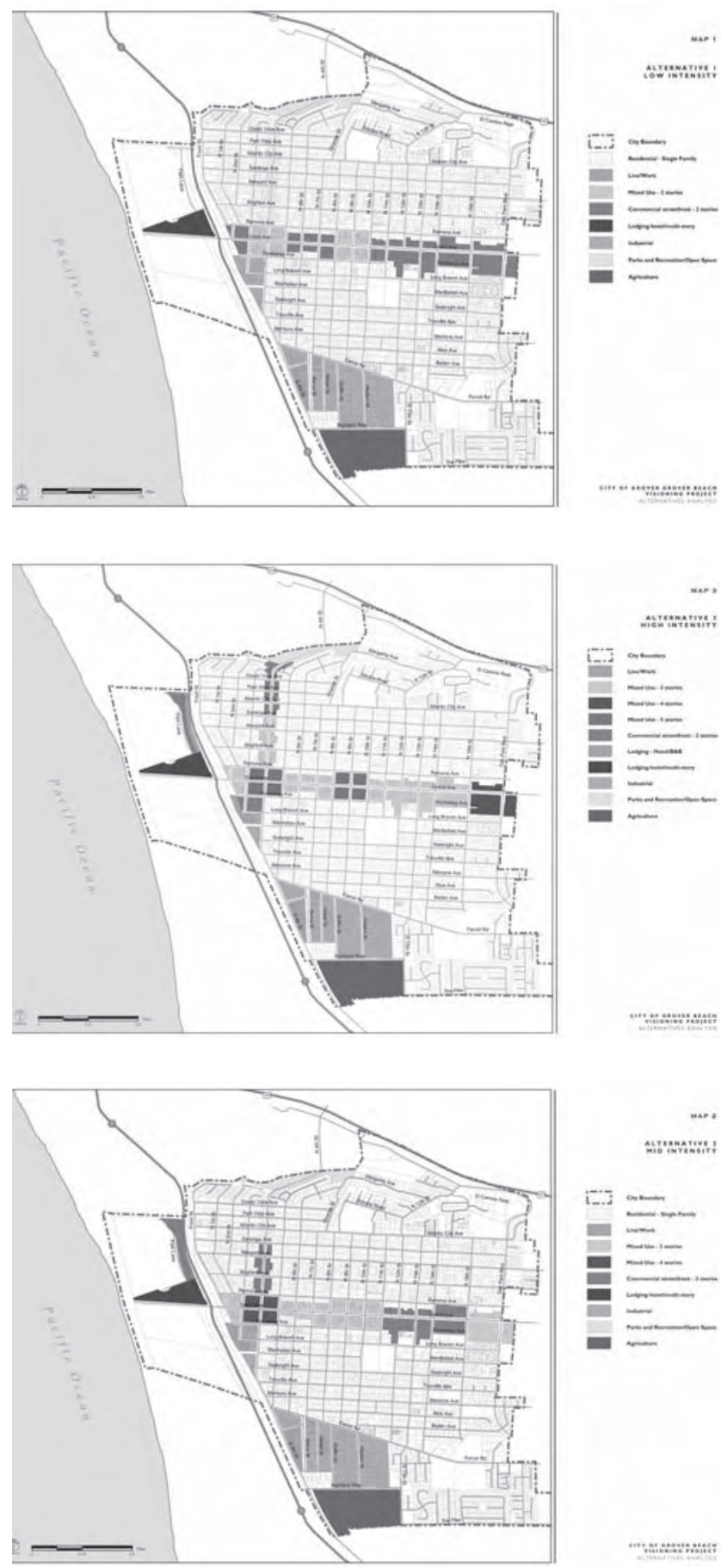

Figure 3. Three Land Use Development scenarios depecting growth alternatives in Grover Beach 